\title{
MAST GELL
}

\section{STABILIZATION AND POI}

Postoperative ileus (POI) is known to prolong hospitalization after abdominal surgery. Although the pathophysiology of $\mathrm{POI}$ is not fully understood, inflammation of the intestine caused by handling during surgery is thought to be important.

Mast cells have a key role in inflammation, and stabilization of these cells has the potential, therefore, to shorten the duration of POI. Mast cell stabilizing agents have already been shown to prevent inflammation in mouse models of POI. "[We] decided to perform a proof-of-principle study in humans [to test] the effect of a mast cell stabilizer on postoperative recovery and intestinal transit," says Guy Boeckxstaens, one of the research team from the Academic Medical Center, Amsterdam, The Netherlands.

Boeckxstaens and colleagues carried out a double-blind, placebo-controlled, randomized, pilot study. A total of 60 patients undergoing abdominal surgery were randomly allocated to receive placebo or ketotifen (a mast cell stabilizer) $4 \mathrm{mg}$ or $12 \mathrm{mg}$ for 6 days, starting 3 days before surgery. The primary end point was gastric emptying $24 \mathrm{~h}$ after surgery, which was determined by scintigraphic imaging following ingestion of $100 \mathrm{ml}$ of radiolabeled tap water.

Gastric emptying in patients treated with $12 \mathrm{mg}$ ketotifen was significantly faster than in the other two groups of patients. This finding supports the theory that mast cells are involved in $\mathrm{POI}$, and that mast cell stabilization could be a potential treatment option for this condition.

"We are currently further exploring the mechanisms of mast cell activation and how mast cells can be better targeted," says Boeckxstaens. "Reduction of POI will have a major impact on patient morbidity, and clearly will lead to reduced hospitalization and costs."

Isobel Franks

Original article The, F. O. et al. The role of mast cell stabilization in treatment of postoperative ileus: a pilot study. Am. J. Gastroenterol. 104, 2257-2266 (2009). 